\title{
Toys in the upper aerodigestive tract: Evidence on their risk as emerging from the ESFBI study
}

\author{
Francesca Foltran ${ }^{\mathrm{a}}$, Dario Gregori ${ }^{\mathrm{b}}$, Desiderio Passàli ${ }^{\mathrm{c}, *}$, Luisa Bellussi $^{\mathrm{c}}$, \\ Giuseppe Caruso $^{\mathrm{c}}$, Francesco Maria Passàli ${ }^{\mathrm{d}}$, Giulio Cesare Passàli ${ }^{\mathrm{e}}$ \\ the ESFBI Study Group ${ }^{1}$ \\ ${ }^{a}$ Department of Surgery, University of Pisa, via Roma n 67, 56100 Pisa, Italy \\ ${ }^{\mathrm{b}}$ Department of Environmental Medicine and Public Health, University of Padova, via 8 Febbraio n 2, 53122 Padova, Italy \\ ${ }^{\mathrm{c}}$ Ear, Nose, and Throat Clinic, Policlinico Le Scotte, University of Siena, v.le M. Bracci, 53100 Siena, Italy \\ ${ }^{\mathrm{d}}$ Ear, Nose, and Throat Clinic, University of Rome Tor Vergata, v.le Oxford n 81, 00133 Roma, Italy \\ ${ }^{\mathrm{e}}$ Ear, Nose, and Throat Clinic, Catholic University of the Sacred Hearth, l.go A. Gemelli n 8, 00168 Roma, Italy
}

Received 16 September 2010; accepted 25 January 2011

Available online 26 February 2011

\begin{abstract}
Objective: Foreign body inhalation/aspiration or ingestion is a relatively common event in young children and, despite many efforts made in several Countries to reach acceptable safety levels for products devoted to children, small toys or toy parts are frequently mentioned among risky foreign bodies. The aim of the present study is to characterize the risk of complications and prolonged hospitalization due to toys inhalation/aspiration or ingestion according to age and gender of patients, FB characteristics and FB location, circumstances of the accident, as emerging from the ESFBI study.

Methods: A retrospective study in major hospitals of 19 European Countries was realized on children aged 0-14 having inhaled/aspired or ingested a toy, with regard to the characteristics of the child and the FB (shape, volume, consistency), the FB location, the hospitalization's details and the occurrence of complications.

Results: In the years 2000-2003 a total of 2094 FB injuries occurred in children aged 0-14 years. Among them 121 (5.8\%) were due to toys (mainly parts of toys) and 95 (4.5\%) occurred in the lower/upper aero-digestive tract. 58 children needed hospitalization. The first determinant of a damage requiring hospitalization is the rigid consistence of the object. Almost $27 \%$ of toys related injuries happened under adults' supervision.

Conclusions: Despite the adoption of preventive strategies, including products modification by manufacturers, has resulted in a decrease of children's mortality rate for chocking in the last decades, our results seem to testify that preventive strategies imposing a regulation of industrial production, even if fundamental, are not sufficient and need to be integrated with other preventive intervention addressed to improve parents ability to be conscious of FB injuries and attentive toward a proper surveillance of children.
\end{abstract}

(C) 2011 Elsevier Ireland Ltd. All rights reserved.

Keywords: Foreign body injuries; Toys; Children; Aero-digestive tract

\section{Introduction}

\footnotetext{
* Corresponding author at: Ear, Nose, and Throat Clinic, Policlinico Le Scotte, University of Siena, Via Anagnina 718, 00118 Rome, Italy. Tel.: +39 3356102667; fax: +39 0679844154 .

E-mail addresses: d.passali@virgilio.it, desiderio@passali.org (D. Passàli).

${ }^{1}$ See Appendix A.
}

Foreign body inhalation/aspiration or ingestion occurs commonly in young children, particularly in those aged from 1 to 3 years, and consequences vary based on the object characteristics, its location, and the patient's age and size [1]. 
The mechanical obstruction of the airways due to foreign body inhalation/aspiration is the primary source of fatal accidents in children younger than 1 , and it represents a major cause of death in children from 1 to 4 years old [2]. Moreover, because of late diagnosis FBs, injury may result in severe complications including asphyxia, pneumonia, atelectasis and bronchiectasis [3]. On the other hand, while most ingested foreign bodies are well tolerated and pass the intestinal tract with no complications, some may cause gastrointestinal perforation or obstruction. The most common complication is entrapment in the esophagus, and possible sequelae include erosion, perforation and even mediastinitis [4].

In case reports and case series reported in scientific literature, small toys or toy parts are frequently mentioned among foreign bodies that may represent choking hazards for children. Many joint efforts have been made in several Countries to reach acceptable safety levels for several kinds of products and to identify prevention standards such as the small parts cylinder (SPC), used to imitate a child under 3 years of age throat to test whether small article may pass or not [5-7].

However, since the evolvement of toys production and the commercialization of new products continuously change the characteristics of potentially risky foreign bodies, a regularly updated surveillance on this issue is needed. The aim of the present study is to characterize the risk of complications and prolonged hospitalization due to toys inhalation/aspiration or ingestion according to age and gender of patients, FB characteristics and FB location, circumstances of the accident, as emerging from the ESFBI study.

\section{Methods}

\subsection{Data collection}

The European Survey on Foreign Bodies Injuries (ESFBI) study collected data on FB injuries in children aged 0-14, from 19 European Hospitals (Austria, Belgium, Bulgaria, Croatia, Czech Republic, Denmark, Finland, Germany, Greece, Italy, Poland, Romania, Slovakia, Slovenia, Spain, Sweden, Swiss, Turkey and United Kingdom). Data on general FB were already published in a previous study [8], in the present paper we only analyzed toys or part of toys injuries. Data on injuries occurred in the years 2000-2003 were identified by means of the International Classification of Diseases, Ninth Revision (ICD-9) codes listed on hospital discharge records. Details on injuries were gathered through a standardized case report form, that includes information regarding: children age and gender, features of the object, circumstances of injury (presence of parents, activity) and the hospitalization's details (lasting, complications and removal details).

\subsection{Toys characteristic definition}

According to the Rimell's classification [9], objects were characterized by size, shape and consistency.

With regard to the size, when the dimensions (in $\mathrm{mm}$ ) of the object were reported, the volume was calculated according to the shape of the objects itself. Such volume measures represent how much space the smallest geometrical figure containing the irregular-shaped FB takes up. Moreover, the ellipticity (the ratio between the maximum and the minimum size reported) was calculated.

\subsection{Statistical analysis}

The analysis was carried out on injuries due to toys. Age and gender injury distributions were assessed. Data regarding adult supervision were also evaluated.

FB location was reported according to ICD9-CM code [10]: nose (ICD932), pharynx and larynx (ICD933) trachea, bronchi and lungs (ICD934), mouth, esophagus and stomach (ICD935).

Descriptive statistics (absolute and relative number or median, I and III quartile according to the categorical or continuous variable characteristics, respectively) were calculated for each considered toy characteristic; FB features distributions by children class age and site of obstruction were assessed.

Two different outcomes were considered: complications and hospitalizations. Complications include all the pathological conditions due to delayed diagnosis or to the attempts of removing the FB. Hospitalization has been defined whether the child was admitted in the hospital for at least 1 day.
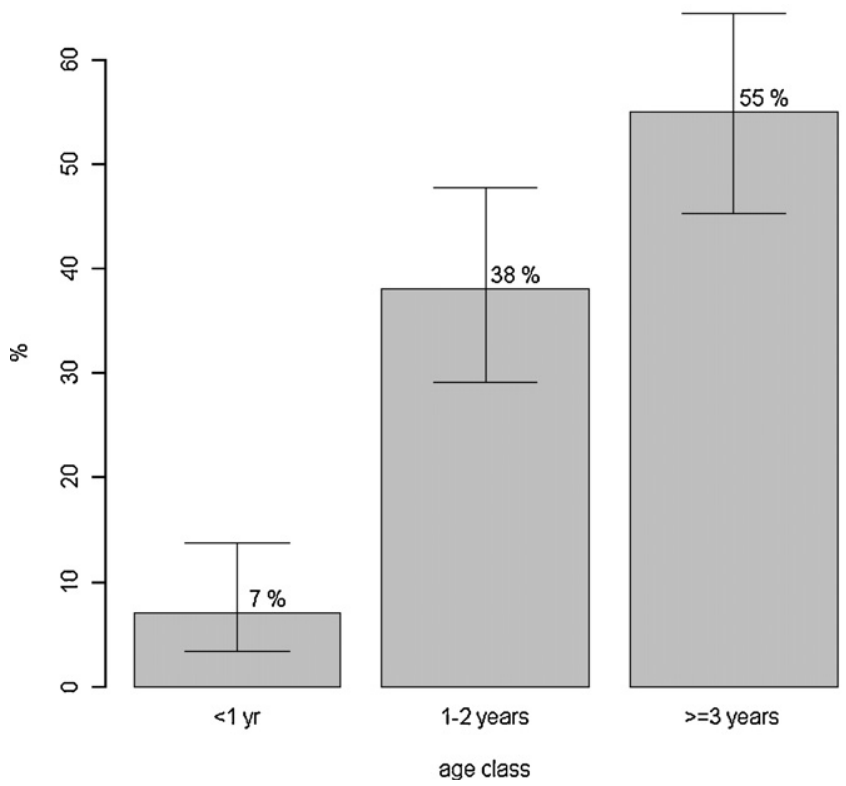

Fig. 1. Distribution of incidence (\%) of FB injuries by age class. Over the bars, $95 \%$ confidence intervals are plotted. 
Table 1

FB location according to ICD9-CM code: nose (ICD932), pharynx and larynx (ICD933) trachea, bronchi and lungs (ICD934), mouth, esophagus and stomach (ICD935). Total amount of toys injuries, complicated injuries and injuries requiring hospitalization are reported.

\begin{tabular}{|c|c|c|c|c|c|}
\hline \multirow[t]{2}{*}{ Location } & \multirow[t]{2}{*}{ Toys related injuries } & \multicolumn{2}{|c|}{ Complications } & \multicolumn{2}{|c|}{ Hospitalization } \\
\hline & & Yes & No & Yes & No \\
\hline Nose & $74 \%(70)$ & $75 \%(3)$ & $74 \%(53)$ & $16 \%(3)$ & $93 \%(54)$ \\
\hline Pharynx and larynx & $6 \%(6)$ & $0 \%(0)$ & $8 \%(6)$ & $11 \%(2)$ & $7 \%(4)$ \\
\hline Trachea, bronchi and lungs & $13 \%(12)$ & $0 \%(0)$ & $12 \%(9)$ & $47 \%(9)$ & $0 \%(0)$ \\
\hline Mouth, esophagus and stomach & $7 \%(7)$ & $25 \%(1)$ & $6 \%(4)$ & $26 \%(5)$ & $0 \%(0)$ \\
\hline Total & 95 & 4 & 72 & 19 & 58 \\
\hline
\end{tabular}

Table 2

Description of the toys which caused the incident.

\begin{tabular}{lc}
\hline Toy description & $N(\%)$ \\
\hline Part of a toy & $17(18 \%)$ \\
Lego type toys & $16(17 \%)$ \\
Spherical toys & $6(6 \%)$ \\
Generic plastic toys & $6(6 \%)$ \\
Wheel of a toy car & $5(5 \%)$ \\
Plastic nail & $4(4 \%)$ \\
Piece of combination box & $4(4 \%)$ \\
Bullet seed & $3(3 \%)$ \\
Plastic coin & $2(2 \%)$ \\
Puzzle piece & $2(2 \%)$ \\
Toy & $29(31 \%)$ \\
\hline
\end{tabular}

The association between outcomes and children's age, adult presence and toys characteristics was computed using unweighted odds ratios and the related 95\% confidence intervals. Odds ratios not possible to be evaluated due to small cell frequency were labeled as NS (not significant).

Analyses were performed using Design and Hmisc libraries from $\mathrm{R}$ version 2.8 [11].

\section{Results}

In the period from January 2000 and the first semester 2003 a total of 2094 FB injuries occurred in children aged $0-14$ years. No significant variation in injury occurrence has been observed, the number of recorded injuries per semester ranging from 290 to 339 without temporal trends. Among them $121(5.8 \%)$ were due to toys and $95(4.5 \%)$ occurred in the lower/upper aero-digestive tract, without any significant temporal trend.

Distribution of incidence of toys injuries by age class is shown in Fig. 1.59 (62\%) of patients were males, while 36 (38\%) were females.

Almost $27 \%$ of toys related injuries happened under adults' supervision.

Details regarding FB location are given in Table 1; data regarding hospitalization and complications were available in 76 and 77 cases, respectively. The total amount of toys injuries, the number of complicated injuries and the number of injuries in which hospitalization is needed are reported for each site.

FB type was known in 94 cases: a short description of the toys that caused the incident is provided in Table 2. Toys volume, shape, ellipticity and consistency by age and by location in aero-digestive tract are described respectively in Tables 3 and 4. Rigid tridimensional objects seem to be most frequently involved in injury occurrence at all ages and they constitute the most frequent find in all the considered locations.

Looking to the outcomes, 58 children needed hospitalization; the median in hospital stay was 1 day in the

Table 3

Toys characteristics by age. Data are first quartile/median/third quartile for continuous variables and percentages (absolute numbers) for categorical variables. $N$ is the number of valid cases for each given variable.

\begin{tabular}{|c|c|c|c|c|}
\hline \multirow{2}{*}{$\begin{array}{l}\text { Foreign body } \\
\text { characteristics }\end{array}$} & \multirow[t]{2}{*}{$N$} & \multicolumn{3}{|l|}{ Age class } \\
\hline & & $<1$ year $(N=7)$ & $1-2$ years $(N=36)$ & $\geq 3$ years $(N=52)$ \\
\hline Volume & 37 & $1225 / 1225 / 1225$ & $80.71 / 175 / 225$ & $65.42 / 150 / 267.95$ \\
\hline Shape & 71 & & & \\
\hline Spherical & & $0 \%(0)$ & $17 \%(5)$ & $21 \%(8)$ \\
\hline 3D & & $50 \%(2)$ & $62 \%(18)$ & $58 \%(22)$ \\
\hline $2 \mathrm{D}$ & & $25 \%(1)$ & $7 \%(2)$ & $8 \%(3)$ \\
\hline 2D circle & & $25 \%$ & $14 \%(4)$ & $13 \%(5)$ \\
\hline Other & & $0 \%(0)$ & $0 \%(0)$ & $0 \%(0)$ \\
\hline Ellipticity & 27 & $3.57 / 3.57 / 3.57$ & $1.6 / 2 / 2.5$ & $1.33 / 1.6 / 2.33$ \\
\hline Consistency & 75 & & & \\
\hline Conforming & & $0 \%(0)$ & $7 \%(2)$ & $5 \%(2)$ \\
\hline Semi-rigid & & $25 \%$ & $34 \%(10)$ & $36 \%(15)$ \\
\hline Rigid & & $75 \%$ & $59 \%(17)$ & $60 \%(25)$ \\
\hline Do not know & & $0 \%(0)$ & $0 \%(0)$ & $0 \%(0)$ \\
\hline
\end{tabular}


Table 4

Toys characteristics by FB location. Data are first quartile/median/third quartile for continuous variables and percentages (absolute numbers) for categorical variables. $N$ is the number of valid cases for each given variable.

\begin{tabular}{|c|c|c|c|c|c|}
\hline \multirow[t]{2}{*}{ Foreign body characteristics } & \multirow[t]{2}{*}{$N$} & \multicolumn{4}{|c|}{ Foreign body location } \\
\hline & & $\begin{array}{l}\text { Nose } \\
(N=70)\end{array}$ & $\begin{array}{l}\text { Pharynx and larynx } \\
(N=6)\end{array}$ & $\begin{array}{l}\text { Trachea, bronchi } \\
\text { and lungs }(N=12)\end{array}$ & $\begin{array}{l}\text { Mouth, esophagus } \\
\text { and stomach }(N=7)\end{array}$ \\
\hline Volume & 37 & $65.42 / 179.5 / 267.95$ & 45/96/113.04 & $105 / 105 / 105$ & $1700 / 2175 / 2650$ \\
\hline Shape & 71 & & & & \\
\hline Spherical & & $23 \%(12)$ & $17 \%(1)$ & $0 \%(0)$ & $0 \%(0)$ \\
\hline $3 \mathrm{D}$ & & $57 \%(30)$ & $67 \%(4)$ & $75 \%(6)$ & $50 \%(2)$ \\
\hline $2 \mathrm{D}$ & & $9 \%(5)$ & $0 \%(0)$ & $12 \%(1)$ & $0 \%(0)$ \\
\hline 2D circle & & $11 \%(6)$ & $17 \%(1)$ & $12 \%(1)$ & $50 \%(2)$ \\
\hline Other & & $0 \%(0)$ & $0 \%(0)$ & $0 \%(0)$ & $0 \%(0)$ \\
\hline Ellipticity & 27 & $1.38 / 1.6 / 2$ & $1.623 / 5.83 / 15$ & $2.33 / 2.33 / 2.33$ & $3.93 / 4.29 / 4.64$ \\
\hline Consistency & 75 & & & & \\
\hline Conforming & & $7 \%(4)$ & $0 \%(0)$ & $0 \%(0)$ & $0 \%(0)$ \\
\hline Semirigid & & $41 \%(23)$ & $17 \%(1)$ & $0 \%(0)$ & $50 \%(2)$ \\
\hline Rigid & & $52 \%(29)$ & $83 \%(5)$ & $100 \%(9)$ & $50 \%(2)$ \\
\hline Do not know & & $0 \%(0)$ & $0 \%(0)$ & $0 \%(0)$ & $0 \%(0)$ \\
\hline
\end{tabular}

Table 5

Odds ratio of complications and of hospitalization with the $95 \%$ confidence intervals are presented. $p$ values are also presented. $N$ number of valid cases for each given variable. NS: not significant, not possible to be evaluated due to small cell frequency. Ref: reference category.

\begin{tabular}{|c|c|c|c|c|c|c|c|c|c|}
\hline \multirow[t]{2}{*}{ Variables } & \multirow[t]{2}{*}{$N$} & \multicolumn{4}{|c|}{ Hospitalization } & \multicolumn{4}{|c|}{ Complications } \\
\hline & & $\begin{array}{l}\text { Yes } \\
(N=19)\end{array}$ & $\begin{array}{l}\text { No } \\
(N=58)\end{array}$ & $\begin{array}{l}\text { OR } \\
(95 \% \mathrm{CI})\end{array}$ & $p$ & $\begin{array}{l}\text { Yes } \\
(N=4)\end{array}$ & $\begin{array}{l}\text { No } \\
(N=72)\end{array}$ & $\begin{array}{l}\text { OR } \\
(95 \% \mathrm{CI})\end{array}$ & $p$ \\
\hline Age class & 95 & & & & & & & & \\
\hline$<1$ year & & $26 \%(5)$ & $0 \%(0)$ & NS & & $25 \%$ & $6 \%(4)$ & $3.25(0.27 ; 3.9)$ & 0.35 \\
\hline $1-2$ years & & $16 \%(3)$ & $45 \%(26)$ & $0.34(0.08 ; 13.3)$ & 0.12 & $0 \%(0)$ & $40 \%(29)$ & NS & \\
\hline$\geq 3$ years & & $58 \%(11)$ & $55 \%(32)$ & Ref & & $75 \%(3)$ & $54 \%(39)$ & Ref & \\
\hline Adult supervision & 65 & & & & & & & & \\
\hline Adult present & & $50 \%(9)$ & $36 \%(17)$ & $1.76(0.59 ; 5.3)$ & 0.31 & $25 \%(1)$ & $41 \%(25)$ & $0.48(0.05 ; 4.88)$ & 0.53 \\
\hline Volume & 37 & $\begin{array}{l}57.75 / 100.5 / \\
945\end{array}$ & $\begin{array}{l}89.23 / 179.5 / \\
267.95\end{array}$ & $1.34(0.92 ; 1.96)$ & 0.13 & $\begin{array}{l}95 / 149.75 / \\
440.88\end{array}$ & $\begin{array}{l}65.42 / 175 / \\
267.95\end{array}$ & $1.05(0.75 ; 1.46)$ & 0.79 \\
\hline Shape & 71 & & & & & & & & \\
\hline Spherical & & $0 \%(0)$ & $24 \%$ & NS & & $25 \%$ & $18 \%(12)$ & $1.08(0.1 ; 1.14)$ & 0.95 \\
\hline $3 \mathrm{D}$ & & $65 \%$ & $57 \%(31)$ & Ref & & $75 \%(3)$ & $59 \%(39)$ & Ref & \\
\hline $2 \mathrm{D}$ & & $12 \%(2)$ & $7 \%(4)$ & $1.41(0.23,8.8)$ & 0.71 & $0 \%(0)$ & $9 \%(6)$ & NS & \\
\hline 2D circle & & $24 \%(4)$ & $11 \%(6)$ & $1.88(0.45 ; 7.93)$ & 0.39 & $0 \%(0)$ & $14 \%(9)$ & NS & \\
\hline Ellipticity & 27 & $1.54 / 2 / 3.26$ & $1.5 / 1.6 / 2.5$ & $0.96(0.76,1.21)$ & 0.72 & $2 / 2.5 / 3.04$ & $1.48 / 1.63 / 2.38$ & $0.96(0.68 ; 1.34)$ & 0.8 \\
\hline Consistency & 75 & & & & & & & & \\
\hline Conforming & & $0 \%(0)$ & $7 \%(4)$ & NS & & $0 \%(0)$ & $6 \%(4)$ & NS & \\
\hline Semirigid & & $17 \%(3)$ & $40 \%(23)$ & Ref & & $25 \%(1)$ & $35 \%(25)$ & Ref & \\
\hline Rigid & & $83 \%(15)$ & $53 \%(30)$ & $3.83(0.99 ; 14.84)$ & 0.05 & $75 \%$ (3) & $59 \%(42)$ & $1.79(0.18 ; 18.11)$ & 0.62 \\
\hline
\end{tabular}

absence of complications, whereas for complications the hospitalization stay was reported in the database for only one child (27 days); removal was performed in the great part of cases by endoscopy while one case required surgery; complications were obstructions [2], pneumonia, esophageal atresia [1] and unilateral nasal odorous discharge [1]. No deaths were observed. In order to verify the association among children age, adult supervision, object characteristics and outcomes, odds ratios of complications and hospitalization, with $95 \%$ confidence intervals, are presented in Table 5; particularly, rigid consistency seems to play a not negligible role in increasing hospitalization risk.

\section{Conclusions}

Aspiration and ingestion of foreign bodies are common events in paediatric patients, which can have severe, even fatal, consequences.

An important advance in the prevention of injuries was the introduction of safety rules for toy design [12]: the 
European regulation bans objects for children under three years having small parts. On the other hand, products designed for children from 3 to 6 years and having small parts must be labeled to warn purchasers not to buy them for children under 3 years $[5,6]$.

The adoption of these preventive strategies mainly based on products modification by manufacturers, has resulted in a decrease of children's mortality rate for chocking in the last decades [7]; however, our results seem to testify that more than 5\% of FB injuries are still due to toys.

The most documented incident is the insertion of a toy or a piece of it in the nose. Even if complications are underreported, severe consequences seem to be rare, probably because the relative inert nature of the plastic material implies a mild tissue inflammation and allows a relatively quick response of the patient upon removal of the FB [13]. Objects are mainly tridimensional and at most with a very small ellipticity ratio of 2 . The first determinant of a damage requiring hospitalization is the rigid consistence of the object: the risk of a stay in hospital longer than 1 day is in fact, three times greater when children inhale or ingest a rigid product, compared with a semi-rigid item.

More than half of injuries due to toys involve children older than three years. This fact seems to testify the effectiveness of regulations finalized to limit the commercialization of products for children up to three years having small parts. However, when details regarding toys are at disposal, in our study the most frequently retrieved foreign bodies are part of toys. Possible explanations include: (i) the commercialization of unsafe products; (ii) when the injury involves young children (younger than 3 years), the accessibility to inappropriate for age toys; (iii) when children are more than 3 years old, poor parents and children education regarding this issue. Incorrect adult supervision is commonly involved in the injury mechanism. In our study, in fact, an adult was present in more than $25 \%$ of cases. These results stress the evidence that preventive strategies imposing a regulation of industrial production, even if fundamental, are not sufficient and need to be integrated with other preventive intervention, addressed to improve parents consciousness and attention toward a proper surveillance of children [14].

\section{Appendix A. The ESFBI Study Group}

\section{Coordinating Center}

Prof. Roberto Corradetti, University of Torino, Italy

Prof. Dario Gregori, University of Torino, Italy

Prof. Desiderio Passali, University of Siena, Italy

Dr. Silvia Snidero, University of Torino, Italy

Austria

Prof. Albegger Klaus, Head of the ENT-Department, Salzburg, Austria Dr. Huttegger Isidor, Universitätsklinik für Kinder- und Jugendheilkunde, Salzburg, Austria

Dr. Schulz Gernot, Universitätsklinik für Kinder- und Jugendheilkunde, Salzburg, Austria
Dr. Bauer Jan, Universitätsklinik für Kinder- und Jugendheilkunde, Salzburg, Austria

Belgium

Prof. Bertrand Bernard, Cliniques Universitaires UCL de Mont-Godinne, ENT Dept., Yvoir, Belgium

Bulgaria

Prof. Karchev Todor, University Hospital "Tzaritza Joanna", Sofia, Bulgaria

Prof. Tzolov Tzolo, University Hospital "Tzaritza Joanna”, Sofia, Bulgaria Croatia

Prof. Mladina Ranko, ORL Department, University Hospital Salata-KBC, Zagreb, Croatia

Dr. Kovac Lana, ORL Department, University Hospital Salata-KBC,

Zagreb, Croatia

Czech Republic

Dr. Slapak Ivo, Pediatric ENT Department of Childrens University Hospital, Brno, Czech Republic

Denmark

Prof. Tos Mirko, Gentofte University Hospital of Copenhagen, Hellerup, Denmark

Prof. Per Caye-Thomasen, Gentofte University Hospital of Copenhagen, Hellerup, Denmark

Finland

Dr. Pitkäranta Anne, Helsinki University Central Hospital, Helsinki,

Finland

Germany

Prof. Jahnke Volker, Charitè Campus Virchow - Klinikum, Berlin, Germany Dr. Göktas Önder, Charitè Campus Virchow - Klinikum, Berlin, Germany Greece

Prof. Nikola Simasko, Democritus University of Thrace, Ent Department, Alexandrupolis, Greece

Dr. Chroni Matilda, Agia Sophia Children Hospital, Ent Department, Athens, Greece

Dr. Ioannis Christopoulos, Agia Sophia Children Hospital, Ent Department, Athens, Greece

Italy

Prof. Desiderio Passàli, Dept. of Otorhinolaryngolgy, University of Siena, Italy Prof. Luisa Bellussi, Dept. of Otorhinolaryngolgy, University of Siena, Italy Dr. Giulio Cesare Passàli, Dept. of Otorhinolaryngolgy, University of Siena, Italy

Dr. Francesco Passàli, Dept. of Otorhinolaryngolgy, University of Siena, Italy

Dr. Valerio Damiani, Dept. of Otorhinolaryngolgy, University of Siena, Italy Poland

Prof. Chmielik Mieczysław, Department of Paediatric Otorhinolaryngology, The Medical University of Warsaw, Poland

\section{Romania}

Prof. Sarafoleanu Dorin, Clinica ORL, Sfanta Maria Hospital, Bucharest, Romania

Dr. Sarafoleanu Codrut, Clinica ORL, "Sfanta Maria Hospital”, Bucharest, Romania

Dr. Dan Cristian Gheorghe, Clinica ORL, "Spitalul de Copii Marie Curie", Bucharest, Romania

\section{Slovakia}

Prof. Jakubíková Janka, Pediatric Otolaryngology Department of Medical Faculty of Comenius University, Bratislava, Slovakia

Slovenia

Prof. Žargi Miha, Department of Otorhinolaryngolgy and Cervicofacial Surgery, University Medical Centre, Ljubljana, Slovenia Dr. Grošelj Aleš, Department of Otorhinolaryngolgy and Cervicofacial Surgery, University Medical Centre, Ljubljana, Slovenia

Dr. Matos Aleš, Department of Otorhinolaryngolgy and Cervicofacial Surgery, University Medical Centre, Ljubljana, Slovenia

Spain

Prof. Rubio Lorenzo, Jefe de la Unidad ORL - Hospital Ruber International, Madrid, Spain

Dr. Cervera Javier, Hospital Niño Jesus, Madrid, Spain 


\section{Sweden}

Prof. Stierna Pontus, Karolinska University Hospital Huttinge, Stockholm, Sweden

\section{Switzerland}

Prof. Pasche Philippe, Service ORL, Centre Hospitalier Universitaire Vaudois, Lausanne, Switzerland

Dr. Cherif Ahmed, Service ORL, Centre Hospitalier Universitaire Vaudois, Lausanne, Switzerland

\section{Turkey}

Prof. Önerci T. Metin, Hacettepe University, Dept. of Otorhinolaryngology, Ankara, Turkey

Dr. Çiftçi Arbay Özden, Hacettepe University, Faculty of Medicine, Dept. of Pediatric Surgery, Ankara, Turkey

Dr. Doğan Riza, Hacettepe University, Faculty of Medicine, Dept. of

Cardiovascular Surgery, Ankara, Turkey

United Kingdom

Prof. Graham John, Royal Free Hospital, London, UK

Dr. Rea Peter, Royal Free Hospital, London, UK

Dr. Obholtzer Rupert, Royal Free Hospital, London, UK

\section{References}

[1] Reilly BK, Stool D, Chen X, Rider G, Stool SE, Reilly JS. Foreign body injury in children in the twentieth century: a modern comparison to the Jackson collection. Int $\mathrm{J}$ Pediatr Otorhinolaryngol 2003;67(Suppl. 1):S171-4.

[2] Reilly J, Thompson J, MacArthur C, Pransky S, Beste D, Smith M, et al. Pediatric aerodigestive foreign body injuries are complications related to timeliness of diagnosis. Laryngoscope 1997;107:17-20.

[3] Sersar SI, Rizk WH, Bilal M, El Diasty MM, Eltantawy TA, Abdelhakam BB, et al. Inhaled foreign bodies: presentation, management and value of history and plain chest radiography in delayed presentation. Otolaryngol Head Neck Surg 2006;134:92-9.

[4] Kay M, Wyllie R. Pediatric foreign bodies and their management. Curr Gastroenterol Rep 2005;7:212-8.

[5] Milkovich SM, Altkorn R, Chen X, Reilly JS, Stool D, Tao L, et al. Development of the small parts cylinder: lessons learned. Laryngoscope 2008;118:2082-6.

[6] Milkovich SM, Rider G, Greaves D, Stool D, Chen X. Application of data for prevention of foreign body injury in children. Int J Pediatr Otorhinolaryngol 2003;67(Suppl. 1):S193-6.

[7] Reilly JS. Risk reduction of injury or death from tracheobronchial foreign bodies in children. Pediatr Pulmonol Suppl 1997; $16: 239$.

[8] Gregori D, Scarinzi C, Morra B, Salerni L, Berchialla P, Snidero S, et al. Ingested foreign bodies causing complications and requiring hospitalization in European children: results from the ESFBI study. Pediatr Int 2010;52:26-32.

[9] Rimell FL, Thome Jr A, Stool S, Reilly JS, Rider G, Stool D, et al. Characteristics of objects that cause choking in children. J Am Med Assoc 1996;274:1763-6.

[10] International Classification of Diseases, 9th Revision, Clinical Modification (ICD-9-CM), 6th edition, 2003.

[11] R Development Core Team. R: a language and environment for statistical computing. Vienna, Austria: R Development Core Team; 2008.

[12] Gregori D. Preventing foreign body injuries in children: a key role to play for the injury community. Inj Prev 2008;14:411.

[13] Koul PA, Wahid A, Bhat TA, Hussain T. Whistle in the bronchus. Ann Thorac Med 2007;2:124-5.

[14] Deal LW, Gomby DS, Zippiroli L, Behrman RE. Unintentional injuries in childhood: analysis and recommendations. Future Child 2000;10: 4-22. 